\title{
A novel ribbed cathode polar plate design in piezoelectric proton exchange membrane fuel cells
}

\author{
H.K. Ma*, S.H. Huang, Y.Z. Kuo \\ Department of Mechanical Engineering, National Taiwan University, No. 1, Sec. 4, Roosevelt Road, Taipei 10617, Taiwan, ROC
}

\section{A R T I C L E I N F O}

\section{Article history:}

Received 6 June 2008

Received in revised form 7 July 2008

Accepted 9 July 2008

Available online $\mathrm{xxx}$

\section{Keywords:}

Piezoelectric

PZT-PEMFC

Rib width

Frequency

Current density

\begin{abstract}
A B S T R A C T
Previous studies have indicated that a novel design for proton exchange membrane fuel cells with a piezoelectric (PZT) device, which is regarded as an actuator for pumping air onto the cathode channel, can offer better performance with higher current generation. These results indicate that piezoelectric proton exchange membrane fuel cells (PZT-PEMFCs) may compress more air into the catalyst layer and thus may enhance electrochemical reactions, resulting in higher current output. At the same time, produced water vapor is pumped out from the cathode channel during the compression process. Previous studies on PZTPEMFCs without ribs showed the strong effect of ohmic and concentration losses. In this study, a shallow rib is chosen to reduce the aforementioned losses and pressure drop in the cathode channel. The rib design is an important parameter that can be used as the support for the membrane electrode assembly (MEA). A transient three-dimensional model is built to simulate and compare the performance of PZT-PEMFCs both with and without ribs. Water vapor, oxygen, and current density profiles in the PZT-PEMFC are studied in detail. The major operating parameters include the rib width and the PZT vibration frequency. Our results show that the ribbed cathode channel can reduce ohmic losses and double current generation. Moreover, at higher PZT vibration frequency $(f=64 \mathrm{~Hz})$, an air-breathing PZT-PEMFC compresses more oxygen into the catalyst layer and thus enhances the electrochemical reaction, resulting in a higher current output $\left(0.208 \mathrm{~A} \mathrm{~cm}^{-2}\right)$.
\end{abstract}

(C) 2008 Elsevier B.V. All rights reserved.

\section{Introduction}

Air-breathing proton exchange membrane fuel cells (ABPEMFCs) have attracted attention as substitutes for currently used batteries. During AB-PEMFC operation, liquid water is transported by electro-osmotic drag, back diffusion, and convection in the membrane. The electro-osmotic drag coefficient has been found to be a function of the water content of the membrane and temperature [1-4]. Generally, the electro-osmotic drag coefficient increases with increasing water content in the membrane. At high water content, the electro-osmotic drag coefficient increases with increasing temperature. Yi and Nguyen [5] showed that PEMFC performance was improved by anode humidification and positive differential pressure between the cathode and anode. Ge and Yi [6] predicted that the dry reactant gases could be successfully humidified internally and could maintain high performance when the PEMFC was operated in counter flow mode. Thus, water transport and management is dependent upon the structure and properties of the cell components, reactant stream humidification, flow field layout, and

\footnotetext{
* Corresponding author. Tel.: +886 2 23629976; fax: +886 223631755 .

E-mail address: skma@ntu.edu.tw (H.K. Ma).
}

structural and wetting properties of the gas diffusion media and micro-porous layer [7].

In general, AB-PEMFCs do not need an additional oxygen supply device; their performance is proportional to the oxygen transfer coefficient [8]. Santa Rosa et al. [9] developed an open-air cathode PEMFC stack with an air fan. This design combined oxidant supply and stack cooling. Using numerical analysis, Zhang et al. [10] presented various stack and cell parameters for stack designs with an array of air-breathing fuel cell cartridges. Matamoros and Bruggmann [11] showed that dehydrating phenomena slightly affected the performance of AB-PEMFCs. Moreover, catalyst loading, relative humidity, temperature, hydrogen stoichiometry, gas-diffusion layer thickness, and cathode structure are important parameters in the performance of AB-PEMFCs [12,13].

Proper flow field design of the AB-PEMFC may help address the water-flooding problem and enhance cell performance. For interdigitated flow fields, the reactant gas can be delivered to the catalyst layer and can increase the electrochemical reaction rate [14]. However, while pin-type flow fields have a lower reactant pressure, they have uneven gas distribution and poor water removal and cell performance [15]. The single-serpentine flow field exhibits better performance than double- and triple-serpentine flow fields [16]. In addition, a new convection-enhanced serpentine flow field has 


\begin{tabular}{|c|c|}
\hline \multicolumn{2}{|c|}{ Nomenclature } \\
\hline$A_{\text {in }}$ & inlet area $\left(\mathrm{m}^{2}\right)$ \\
\hline$A_{\text {PZT }}$ & piezoelectric area $\left(\mathrm{m}^{2}\right)$ \\
\hline$D_{\text {eff }}$ & effective diffusion coefficient $\left(\mathrm{m} \mathrm{s}^{-1}\right)$ \\
\hline$f$ & frequency of PZT (Hz) \\
\hline$F$ & Faraday constant $\left(96,439 \mathrm{C} \mathrm{mole}^{-1}\right)$ \\
\hline$h$ & enthalpy (kJ) \\
\hline$i$ & current $(A)$ \\
\hline$J_{i}$ & species diffusive flux $\left(\mathrm{mol} \mathrm{m}^{-2} \mathrm{~s}^{-1}\right)$ \\
\hline$j_{\mathrm{T}}$ & transfer current $(\mathrm{A})$ \\
\hline$j_{0}$ & $\begin{array}{l}\text { reference current density at a known open circuit } \\
\text { voltage }\left(\mathrm{A} \mathrm{m}^{-3}\right)\end{array}$ \\
\hline$k_{\text {eff }}$ & effective thermal conductivity ( $\left.\mathrm{W} \mathrm{m}^{-1} \mathrm{~K}^{-1}\right)$ \\
\hline M & mass (kg) \\
\hline$N$ & amount of species \\
\hline$P$ & pressure $\left(\mathrm{N} \mathrm{m}^{-2}\right)$ \\
\hline$R$ & gas constant $\left(\mathrm{J} \mathrm{mol}^{-1} \mathrm{~K}^{-1}\right)$ \\
\hline$t$ & time $(\mathrm{s})$ \\
\hline$T$ & temperature $(\mathrm{K})$ \\
\hline$V_{\mathrm{a}}$ & anode inlet velocity $\left(\mathrm{m} \mathrm{s}^{-1}\right)$ \\
\hline$V_{\mathrm{c}}$ & cathode inlet velocity $\left(\mathrm{m} \mathrm{s}^{-1}\right)$ \\
\hline$V_{\mathrm{PZT}}$ & motion equation of the piezoelectric device $\left(\mathrm{m} \mathrm{s}^{-1}\right)$ \\
\hline$Y_{i}$ & mass fraction of $i$ th species \\
\hline$\forall$ & volume $\left(\mathrm{m}^{3}\right)$ \\
\hline \multicolumn{2}{|c|}{ Greek letters } \\
\hline$\varepsilon$ & porosity \\
\hline$\eta$ & over potential (V) \\
\hline$\kappa$ & permeability $\left(\mathrm{m}^{2}\right)$ \\
\hline$\mu$ & viscosity $\left(\mathrm{kg} \mathrm{m}^{-1} \mathrm{~s}^{-1}\right)$ \\
\hline$\rho$ & density $\left(\mathrm{kg} \mathrm{m}^{-3}\right)$ \\
\hline$\tau$ & shear stress $\left(\mathrm{N} \mathrm{m}^{-2}\right)$ \\
\hline$\phi$ & equivalence ratio \\
\hline$\omega_{i}$ & production rates $\left(\mathrm{kg} \mathrm{m}^{-3} \mathrm{~s}^{-1}\right)$ \\
\hline \multicolumn{2}{|c|}{ Subscript } \\
\hline act. & actual \\
\hline stoi. & stoichiometry \\
\hline
\end{tabular}

been proposed by Xu and Zhao [17] to increase the mass transport rate and remove liquid water trapped in the porous media. Furthermore, the parallel flow field with an incorporated baffle exhibited better performance because the baffle effect forces the reactant gas to pass through the diffusion layer [18]. Moreover, Ma et al. $[19,20]$ have proposed a novel cathode channel design that utilizes the piezoelectric (PZT) effect in AB-PEMFC systems, known as the PZT-PEMFC. The PZT-PEMFC can feed air into the cathode channel through a gas pump with a piezoelectric actuation structure. A higher PZT vibration frequency leads to a higher oxygen concentration at the cathode channel, and most of the produced water vapor can be pumped out of the cathode channel by PZT vibrations. This design can reduce the water-flooding problem and increase cell efficiency.

Studies have shown that a ribbed design affects cell performance and species distribution, and that a narrower channel with a wider rib spacing yields better performance [21,22]. Although PZT-PEMFCs may increase cell efficiency and reduce water flooding, a rib-free design may induce a large resistance. Thus, ribs are necessary on the cathode side of the PZT-PEMFC. Jeong et al. [23] showed that a single cell with a cathode open area of $77 \%$ exhibited the best performance. This result was related to oxygen transport from the atmosphere to the catalyst layer. Hottinen et al. [24] concluded that the resistance of a larger open cathode area increased tremendously, adversely affecting performance. Thus, a novel cathode side design with ribs in the PZT-PEMFC is proposed in this study. In addition, a valveless design with four air ports is applied in the PZT-PEMFC, differing from previous studies [19,20]. A transitional three-dimensional model [25], based on the semi-implicit method for pressure line equations consistent (SIMPLEC) procedure, is used to calculate the effect of ribs on the performance of the PEMFC at different PZT frequencies.

\section{Mechanisms of PZT-PEMFC}

The PZT-PEMFC (Fig. 1) contains a piezoelectrically actuated micro-diaphragm that is installed in the cathode channel. This device is regarded as an original gas pump design and can draw air into the cathode channel without an external air pump. While the actuator moves outward, the volume of the cathode channel increases, and the air is drawn into the chamber (Fig. 2). However, when the actuator moves inward, the volume of the cathode channel decreases, and the air is compressed into the catalyst layer. Previous studies have proposed an ideal air-breathing PZT-PEMFC cycle that describes four piezoelectric actuation processes. In addition, the motion of the PZT device was assumed to be a step function $[19,20]$. In this study, a sine function was applied for the motion of PZT device as it may improve both the electrochemical reaction in the catalyst layer and the power output.

In addition, the PZT-PEMFC can also be used in stacks. Fig. 3 shows that two cathode channels and two-cell stacks can be driven by one PZT device.

\subsection{Equivalence ratio}

The equivalence ratio, defined as the actual fuel-to-air ratio divided by theoretical fuel-to-air ratio, is an important parameter
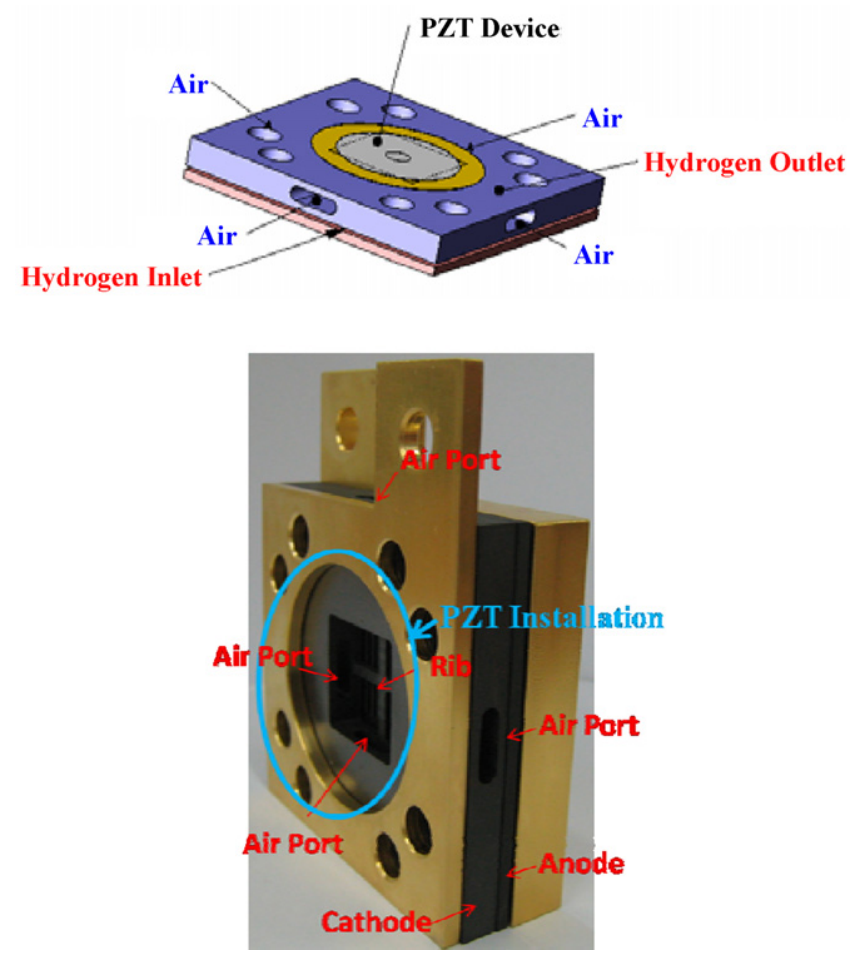

Fig. 1. The outlook of a PZT-PEMFC system. 


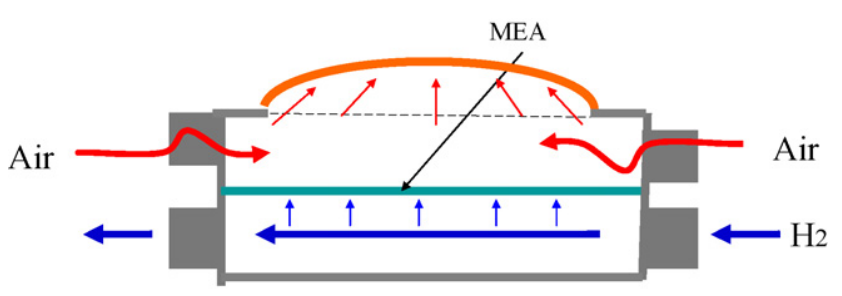

(a) Sucked air into the channel

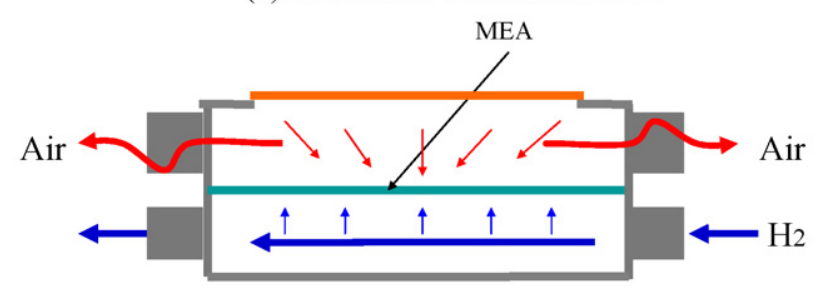

(b) Rejected gases out of the channel

Fig. 2. Actuating mechanisms in a PZT-PEMFC system.

for discussing air-fuel mixing phenomena in internal combustion engines [26]. Similarly, the equivalence ratio is also an important parameter for air-breathing PZT-PEMFCs. The theoretical demand of air for generating $1 \mathrm{~A}$ of current is $17.96 \mathrm{mg} \mathrm{min}^{-1}$, and the

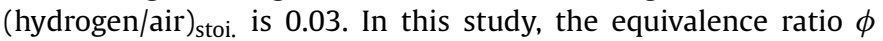
is defined as the ratio of (hydrogen/air)act. to (hydrogen/air) stoi. Fuel-rich conditions $(\phi>1)$ are found in air-deficient and incomplete hydrogen reactions at low PZT vibration frequencies. On the contrary, fuel lean conditions $(\phi<1)$ are found at high PZT vibration frequencies, where sufficient air is drawn into the cathode channel, resulting in an increase in hydrogen consumption.

\subsection{Actuation analysis of PZT-PEMFC}

The driving forces at the anode and cathode inlets are different. The inlet hydrogen velocity at the anode is assumed to be constant. However, the inlet air velocity at the cathode is driven by PZT vibrations. Thus, the velocity $V$ is divided into the anode velocity $V_{\mathrm{a}}$ and cathode velocity $V_{\mathrm{c}}$. The equation of motion for the PZT is a sine function given by

$\overrightarrow{V_{\mathrm{PZT}}}=\frac{\mathrm{d}}{\mathrm{d} t}\left\{-0.0005 \times\left(\sin \left(2 \pi f t-\frac{\pi}{2}\right)\right)\right\}$.

Also, the inflow and outflow periods in the channel as induced by the sine function are shown in Fig. 4 . The inlet air-flow rate at

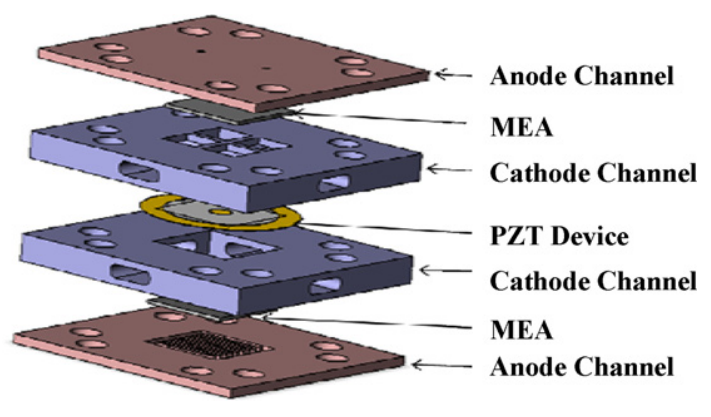

Fig. 3. The outlook of a PZT-PEMFC stack.

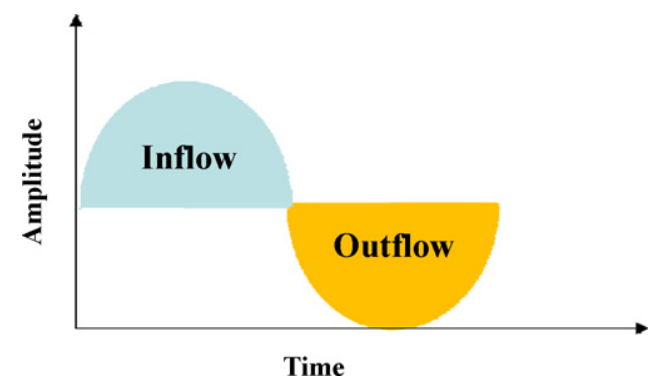

Fig. 4. The sine function of periodical flow at cathode.

the cathode is expressed by the Reynolds Transport Theorem as

$$
\begin{aligned}
\frac{D M}{D t} & =\frac{D(\rho \forall)}{D t} \\
& =\frac{\partial}{\partial t} \int_{C \forall} \rho \mathrm{d} \forall+\int_{C S, \text { PZT }} \rho \overrightarrow{V_{\mathrm{PZT}}} \cdot \vec{n} \mathrm{~d} A+\int_{C S, \text { in }} \rho_{\mathrm{C}} \vec{V}_{\mathrm{C}} \cdot \vec{n} \mathrm{~d} A=0 .
\end{aligned}
$$

The gas density is expressed by the equation of state for an ideal gas, so the mass conservation equation is derived as

$\frac{1}{R} \frac{\partial}{\partial t} \int_{C \forall} \frac{P}{T} \mathrm{~d} \forall+\rho_{\mathrm{cs}, \mathrm{PZT}} \overrightarrow{V_{\mathrm{PZT}}} A_{\mathrm{PZT}}-\rho_{\mathrm{c}} \vec{V}_{\mathrm{c}} A_{\text {in }}=0$.

The inlet velocity at the cathode, $\vec{V}_{c}$, is derived as

$\vec{V}_{\mathrm{c}}=\frac{1}{\rho_{\mathrm{C}} A_{\mathrm{in}}}\left[\frac{1}{R} \frac{\partial}{\partial t} \int_{C \forall} \frac{P}{T} \mathrm{~d} \forall+\rho_{\mathrm{CS}} \overrightarrow{V_{\mathrm{PZT}}} A_{\mathrm{PZT}}\right]$.

\section{Theoretical model for PZT-PEMFC}

A numerical model of the novel fuel cell, based on the SIMPLEC procedure, has also been developed. The assumptions are as follows:

(1) The reactants and products are treated as ideal gases.

(2) The Stefan-Maxwell equations are applied to multispecies diffusion.

(3) Contact electrical and heat resistances among the channel layer, diffusion layer, catalyst layer, and membrane are ignored.

(4) The Nernst-Planck equation is used for proton transport through the membrane.

(5) Ohm's law is applied across the entire region of the polarization curve.

(6) The porosity and permeability of the porous media are uniform, and the porous media are isotropic and homogeneous.

(7) The effect of gravity is ignored.

(8) The amplitude of the PZT device is assumed constant for all frequencies, and the motion of PZT device is assumed to be a sine function.

(9) The water in the fuel cell is assumed to be vapor.

(10) The relative humidity of fuel and air is $100 \%$.

The membrane electrode assembly (MEA) parameters refer to a DuPont membrane, and the dimensions of the PEMFC are shown in Fig. 5. The compositions of the inlet humidified fuel and air are shown in Table 1 . In addition, the inlet fuel velocity is $1 \mathrm{~m} \mathrm{~s}^{-1}$. The inlet air velocities vary with different PZT frequencies, as shown in Table 2. 


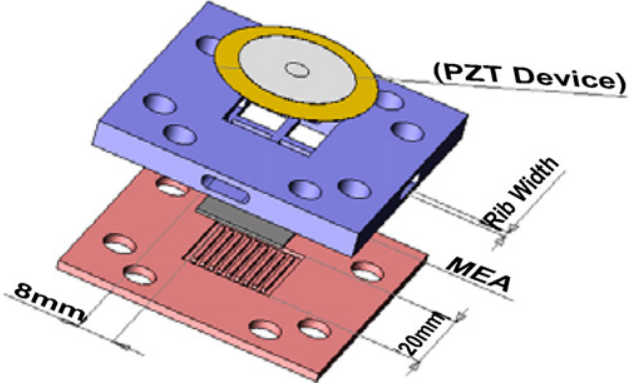

Fig. 5. Dimensions of PZT-PEMFC.

Table 1

Gas composition of fuel and air at inlet conditions

\begin{tabular}{llr}
\hline Fuel & Hydrogen & $43.9 \%$ \\
& Water vapor & $56.1 \%$ \\
& Nitrogen & $69.8 \%$ \\
Air & Oxygen & $22.1 \%$ \\
& Water vapor & $8.1 \%$ \\
\hline
\end{tabular}

Unit: molar concentration.

\subsection{Channel layer}

The governing equations in the channel include the continuity, momentum, and species equations. The continuity equation is

$\frac{\partial \rho}{\partial t}+\nabla \cdot(\rho \vec{V})=0$.

The momentum equation is

$\frac{\partial}{\partial t}(\rho \vec{V})+(\nabla \cdot \rho \vec{V} \vec{V})=-\nabla p+\nabla \cdot \tau$.

The energy equation is

$\frac{\partial}{\partial t}(\rho h)+\nabla \cdot(\rho \vec{V} h)=\nabla \cdot q+\tau: \nabla \vec{V}+\frac{\mathrm{d} p}{\mathrm{~d} t}$.

The species equation is

$\frac{\partial}{\partial t}\left(\rho Y_{i}\right)+\nabla \cdot\left(\rho \vec{V} Y_{i}\right)=\nabla \cdot J_{i}$,

where $Y_{i}$ is the mass fraction in the gas phase of the $i$ th species. $J_{i}$ is the diffusive flux, which can be expressed as

$J_{i}=\rho D_{i, \mathrm{eff}} \nabla Y_{i}+\frac{\rho Y_{i}}{M} D_{i, \mathrm{eff}} \nabla M-\rho M \sum_{j} D_{i, \mathrm{eff}} \nabla Y_{j}$

$$
-\rho \nabla M \sum_{j} D_{i, \mathrm{eff}} \nabla Y_{j}
$$

where $\rho D_{i, e f f} \nabla Y_{i}$ is the Fickian diffusion coefficient, which is induced by the concentration gradient. Other terms are the corrections of multiple species within the porous medium. The fluid diffusion coefficient should be modified to $D_{i, \mathrm{eff}}$, which is derived by Bruggeman [27].

Table 2

Operating parameters

\begin{tabular}{lll}
\hline & $V_{\mathrm{a}}$ & $1 \mathrm{~m} \mathrm{~s}^{-1}$ \\
Anode inlet & Pressure & $1 \mathrm{~atm}$ \\
& Temperature & $323 \mathrm{~K}$ \\
& $V_{\mathrm{c}}$ & Eq. (4), $\mathrm{m} \mathrm{s}^{-1}$ \\
Cathode inlet & Pressure & $1 \mathrm{~atm}$ \\
& Temperature & $323 \mathrm{~K}$ \\
\hline
\end{tabular}

\subsection{Diffusion layer}

For porous media, the governing equations should be modified by the porosity $\varepsilon$ and the permeability $k$ of the media. The governing equations are as follows:

The Continuity equation is

$\frac{\partial}{\partial t}(\varepsilon \rho)+\nabla \cdot(\varepsilon \rho \vec{V})=0$.

The momentum equation is

$\frac{\partial}{\partial t}(\varepsilon \rho \vec{V})+(\nabla \cdot \varepsilon \rho \vec{V} \vec{V})=-\varepsilon \nabla p+\nabla \cdot(\varepsilon \tau)+\frac{\varepsilon^{2} \mu \vec{V}}{k}$

where $\varepsilon^{2} \mu V / k$ is Darcy's drag force describing the fluid flowing through the porous media.

The energy equation is written as

$\frac{\partial}{\partial t}(\varepsilon \rho h)+\nabla \cdot\left(\varepsilon \rho \vec{V}_{\mathrm{a}} h\right)=\nabla \cdot q+\varepsilon \tau: \nabla \vec{V}_{\mathrm{a}}+\varepsilon \frac{\mathrm{d} p}{\mathrm{~d} t}-j_{\mathrm{T}} \eta+\frac{i \cdot i}{\sigma}$.

The species equation is

$\frac{\partial}{\partial t}\left(\varepsilon \rho Y_{i}\right)+\nabla \cdot\left(\varepsilon \rho \vec{V}_{\mathrm{a}} Y_{i}\right)=\nabla \cdot J_{i}$

\subsection{Catalyst layer}

The important governing equations in the catalyst layer are the species and current conservation equations. Because the electrochemical reaction and current generation take place in this layer, the species and current conservation equations should be written in the forms given below.

The species equation is

$\frac{\partial}{\partial t}\left(\varepsilon \rho Y_{i}\right)+\nabla \cdot\left(\varepsilon \rho \vec{V} Y_{i}\right)=\nabla \cdot J_{i}+\omega_{i}$,

where $\omega_{i}$ is the production rate in the gas phase of the $i$ th species. The transfer current $j_{\mathrm{T}}$ can be expressed by the Butler-Volmer equation as

$j_{\mathrm{T}}=\frac{j_{0}}{\prod_{k=1}^{N}\left[\Lambda_{k, \mathrm{ref}}\right]^{\alpha_{k}}}\left[\exp \left(\frac{\alpha_{\mathrm{a}} F}{R T} \eta\right)-\exp \left(\frac{\alpha_{\mathrm{c}} F}{R T} \eta\right)\right] \prod_{k=1}^{N}\left[\Lambda_{k}{ }^{\alpha_{k}}\right.$,

where $\eta$ is an over potential, defined as the difference between the solid potential and the porous (or liquid) potential.

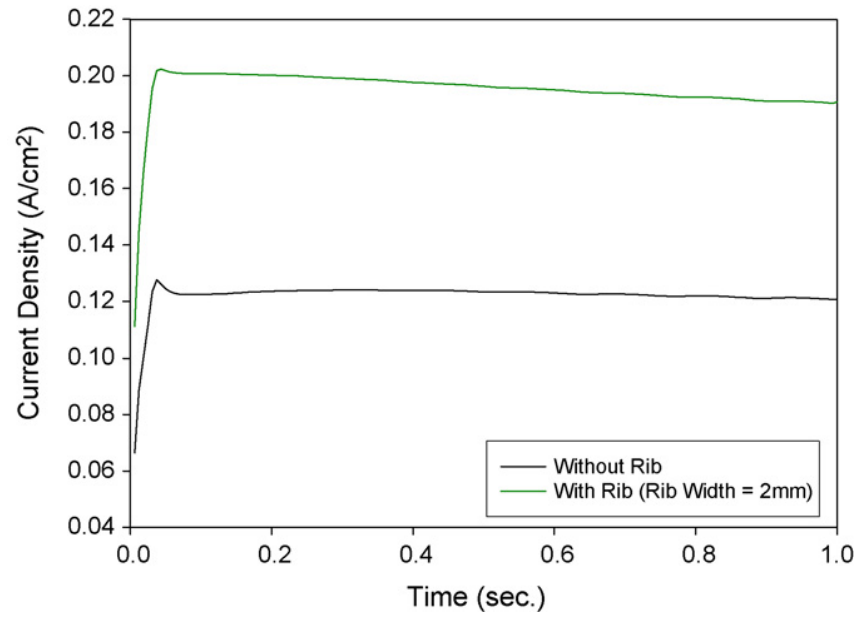

Fig. 6. Current density profiles with/without $\mathrm{rib}(f=8 \mathrm{~Hz})$. 


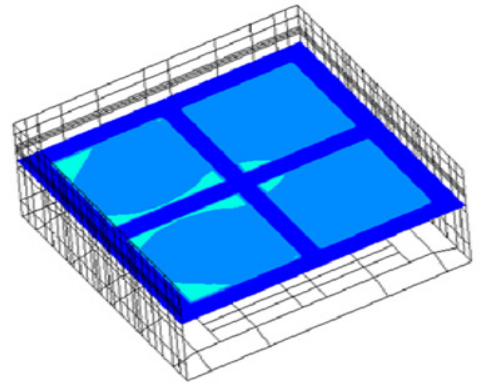

$\mathrm{t}=0.5 \mathrm{sec}$.

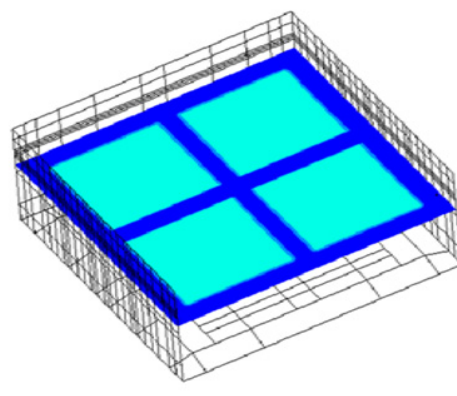

$\mathrm{t}=1.0 \mathrm{sec}$.

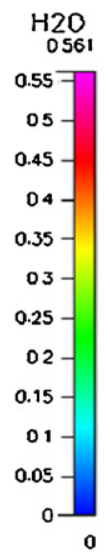

Fig. 7. Water vapor distribution in different time (rib width $=2 \mathrm{~mm}, f=8 \mathrm{~Hz}$ ).

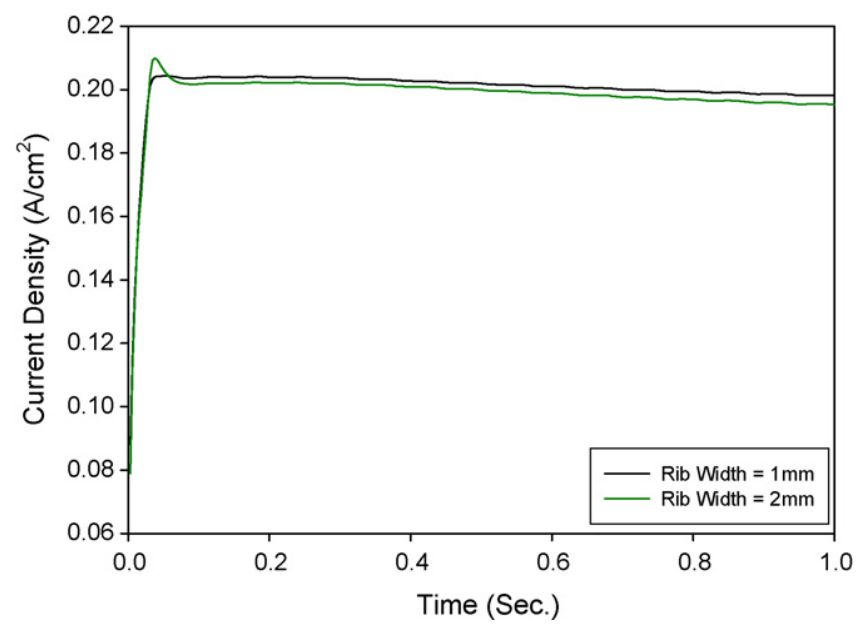

Fig. 8. Current density profiles with different rib width $(f=16 \mathrm{~Hz})$.

The current conservation equation is given by

$\nabla \cdot i=0$.

Because the current flows through the porous medium, it can be divided into two parts. The first part is

$i=i_{\mathrm{f}}+i_{\mathrm{s}}$,

where $i_{\mathrm{f}}$ is the current flowing through the fluid, and $i_{\mathrm{s}}$ is the current flowing through the solid. Because they are porous media, the electrons transfer from fluid to solid and solid to fluid. Thus, the transfer current can be written as

$j_{\mathrm{T}}=\nabla \cdot i_{\mathrm{s}}=-\nabla \cdot i_{\mathrm{f}}$

Using Ohm's law, this can be changed to

$\nabla \cdot\left(\sigma_{\mathrm{f}} \nabla \varphi_{\mathrm{f}}\right)=-\nabla \cdot\left(\sigma_{\mathrm{s}} \nabla \varphi_{\mathrm{s}}\right)=j_{\mathrm{T}}$.

\section{Results and discussion}

A novel ribbed PZT-PEMFCs design has been developed, and a three-dimensional, transitional model has been successfully built to analyze its performance and primary phenomena.

\subsection{Influence of rib design on current density}

The rib design is an important parameter in the fuel cell for reducing internal resistance and for preventing MEA fracture due to the pressure difference between the anode and cathode. However, previous studies $[19,20]$ did not have any ribs in the cathode channel. As shown in Fig. 6, only the unribbed design has a small current density, $0.12 \mathrm{~A} \mathrm{~cm}^{-2}$, due to higher resistance. A ribbed cathode channel can reduce cathode open air area, which decreases the resistance and doubles the current density [22,23]. However, the ribbed design has a water-accumulation problem. Therefore, the current decreases with time. As shown in Fig. 7, water vapor may be blocked and may be accumulated near the rib with time.

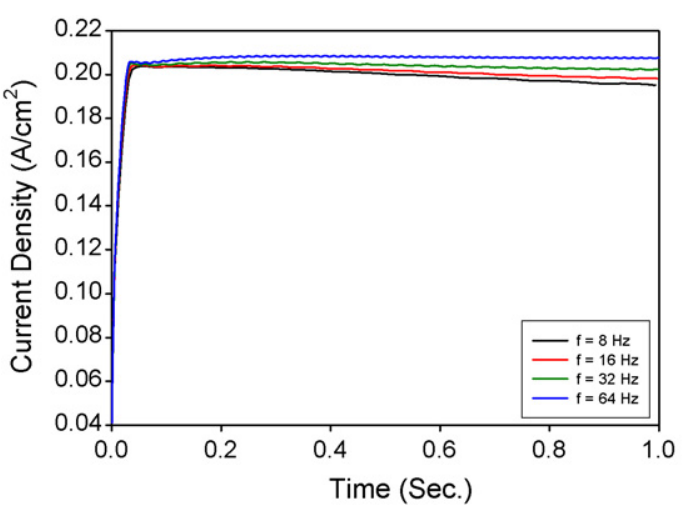

Rib width $=1 \mathrm{~mm}$

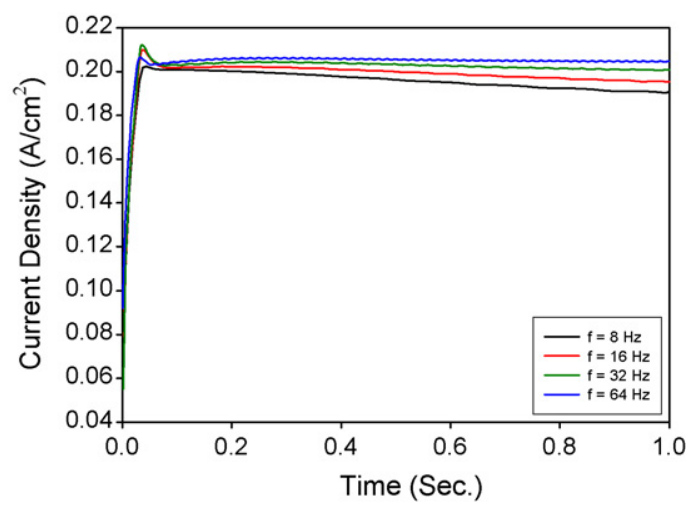

Rib width $=2 \mathrm{~mm}$

Fig. 9. Current density profiles under different PZT frequencies. 


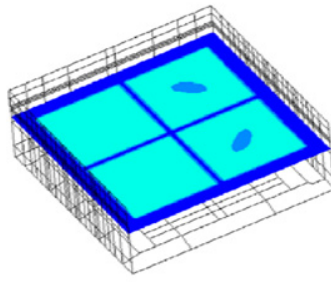

$\mathbf{f}=\mathbf{8} \mathrm{Hz}$

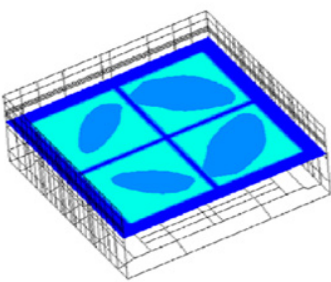

$\mathrm{f}=16 \mathrm{~Hz}$

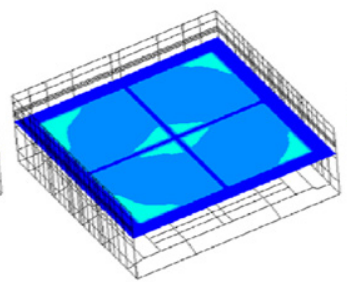

$\mathrm{f}=32 \mathrm{~Hz}$

(Rib width $=1 \mathrm{~mm}$ )

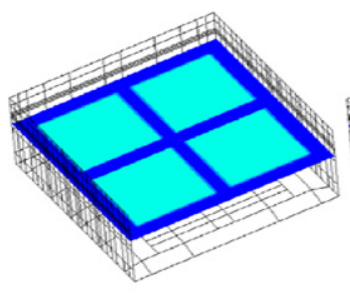

$\mathrm{f}=8 \mathrm{~Hz}$

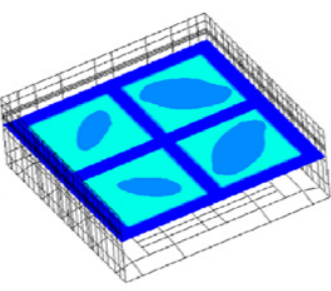

$\mathrm{f}=16 \mathrm{~Hz}$

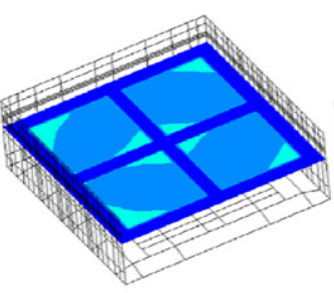

$\mathrm{f}=32 \mathrm{~Hz}$

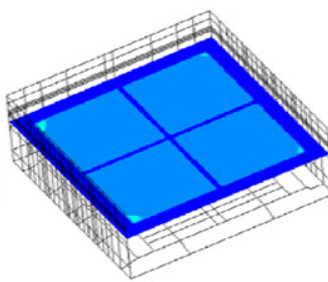

$\mathrm{f}=64 \mathrm{~Hz}$

$\mathrm{H} 2 \mathrm{O}$
0561
$0.55-$
$0.5-$
$0.45-$
$0.4-$
$0.35-$
$03-$
$0.25-$
$0.2-$
$0.15-$
$0.1-$
$0.05-$
0

$H_{2} \mathrm{O}$
0561
$0.55-$
$0.5-$
$0.45-$
$0.4-$
$0.35-$
$03-1$
$0.25-$
$0.2-$
$0.15-$
$0.1-$
$0.05-$
$0-1$
0

$($ Rib width $=2 \mathrm{~mm})$

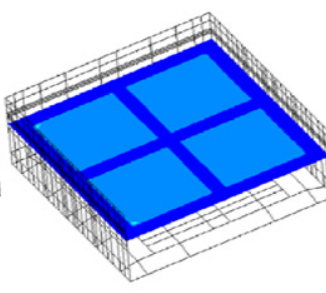

$f=64 \mathrm{~Hz}$

Fig. 10. Water vapor profiles under different rib width.

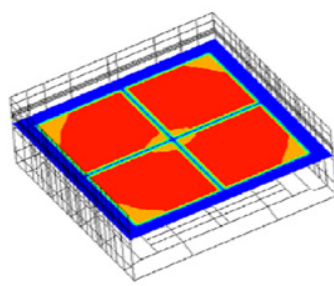

$\mathrm{f}=\mathbf{8 \mathrm { Hz }}$

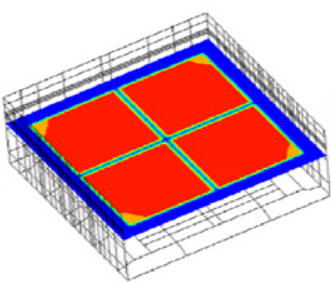

$f=16 \mathrm{~Hz}$

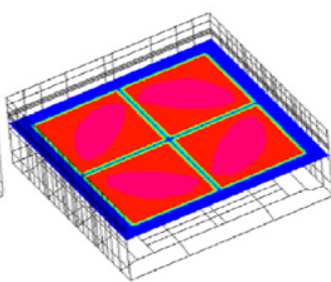

$\mathrm{f}=32 \mathrm{~Hz}$

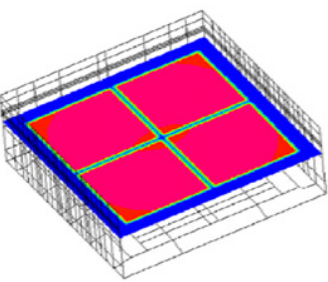

$f=64 \mathrm{~Hz}$

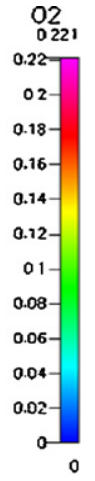

(Rib width $=1 \mathrm{~mm}$ )

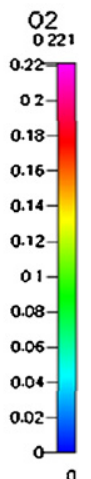

(Rib width $=2 \mathrm{~mm}$ )

Fig. 11. Oxygen concentration profiles under different rib width. 


\subsection{Influence of rib width on current density}

Although water may accumulate near the rib and may reduce internal resistance in wider ribs, Fig. 8 shows that both a wider rib and a thinner rib have a slight effect on cell performance. However, a current overshoot may occur at the initial stage in the wide rib case. The current will then decay and be lower than in the thin rib case.

\subsection{Influence of PZT frequency on current density}

As the PZT vibrates at low frequencies, it is shown in Fig. 9 that current generation is lower compared with high PZT vibration frequencies. However, a current overshoot occurs in the wide rib case, especially at the high PZT vibration frequency. In addition, the current decreases with time at the low PZT vibration frequency $(f=8$, $16 \mathrm{~Hz}$ ) due to the lower air-flow rate in the cathode channel. Fig. 10 illustrates that the current may decay with time because the accumulated water vapor cannot be pumped out immediately in the cathode channel with low PZT vibration frequencies. The simulations show that the water distribution in the cathode channel is only slightly different under both rib-width cases. Fig. 11 also shows that the rib width slightly affects oxygen distribution in the cathode channel. Therefore, it may be the reason for the slight difference in current density between the two different widths (Fig. 9).

The simulation result of this study is a quasi-steady state, and it consists of 64 cycles in $1 \mathrm{~s}$, i.e., $f=64 \mathrm{~Hz}$. In order to reduce computational time, the time scale is chosen as $1 \mathrm{~s}$.

\subsection{Influence of equivalence ratio on current density}

When the PZT vibrates at high frequencies, more air can be drawn into the cathode channel, leading to a reduction in the equivalence ratio. Therefore, higher current density can be found at $f=64 \mathrm{~Hz}$, where the equivalence ratios are 1.72 and 1.54 with rib sizes of 1 and $2 \mathrm{~mm}$, respectively (Table 3 ). In contrast, with higher equivalence ratios, less air will be drawn into the cathode channel at low PZT frequencies. When the rib width increases from 1 to $2 \mathrm{~mm}$, the difference in the equivalence ratio is $2.76 \%$ at a high PZT frequency of $f=64 \mathrm{~Hz}$. However, the difference in equivalence ratio is only $0.35 \%$ at a low PZT frequency of $f=8 \mathrm{~Hz}$.

The simulations indicate that the equivalence ratio is not affected by the rib width (Fig. 12). In addition, the current density is high at high frequencies. Both of the different rib widths generate almost the same current density, 0.205 and $0.208 \mathrm{~A} \mathrm{~cm}^{-2}$, using 1 and $2 \mathrm{~mm}$ rib widths, respectively, at $f=64 \mathrm{~Hz}$. Therefore, the effect of the PZT vibration frequency is stronger than the effect of rib width in the air-flow rate.

Table 3

Air-flow rate at different PZT frequencies and equivalence ratio at the same time $(t=1 \mathrm{~s})$

\begin{tabular}{lcc}
\hline PZT frequency $(\mathrm{Hz})$ & Air-flow rate $\left(\mathrm{mg} \mathrm{s}^{-1}\right)$ & Equivalence ratio \\
\hline Rib width = $1 \mathrm{~mm}$ & & \\
8 & 17.19 & 6.08 \\
16 & 36.90 & 3.04 \\
32 & 73.89 & 1.72 \\
64 & 130.50 & \\
Rib width =2 mm & & 12.88 \\
8 & 17.43 & 6.16 \\
16 & 36.45 & 3.05 \\
32 & 73.50 & 1.54 \\
64 & 145.80 & \\
\hline
\end{tabular}

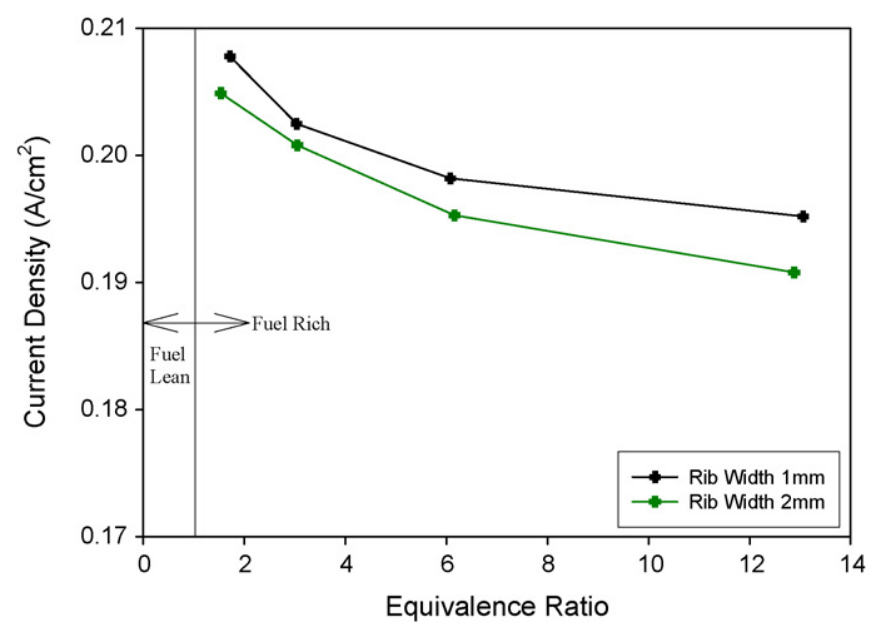

Fig. 12. Current density profiles under different equivalent ratio.

\section{Conclusions}

A novel ribbed PZT-PEMFCs design has been developed, and a three-dimensional, transitional model has been successfully built to consider its primary phenomena and fuel cell performance. A ribbed cathode channel can reduce the internal resistance and can double the current density. However, the ribbed design may cause the accumulation of water vapor near the rib. At higher PZT vibration frequency $(f=64 \mathrm{~Hz})$, an air-breathing PZT-PEMFC compresses more oxygen into the catalyst layer and thus enhances the electrochemical reaction, resulting in a higher current output. At the same time, the accumulated water vapor may be pumped out from the cathode channel during the compression process. In addition, the effect of PZT vibration frequency is stronger than the effect of the rib width on the air-flow rate and current density. The optimal current density for the ribbed PZT-PEMFCs in the cathode below $0.7 \mathrm{~V}$ is $0.208 \mathrm{~A} \mathrm{~cm}^{-2}$ at $f=64 \mathrm{~Hz}$.

\section{Acknowledgement}

This research was funded by the National Science Council of the Republic of China (NSC 96-2221-E-002-074-MY2).

\section{References}

[1] T.F. Fuller, J. Newman, J. Electrochem. Soc. 139 (1992) 1332-1337.

[2] T.A. Zawodzinski, J. Davey, J. Valerio, S. Gottesfeld, Electrochim. Acta 40 (1995) 297-302.

[3] S.H. Ge, B.L. Yi, P.W. Ming, J. Electrochem. Soc. 153 (2006) A1443-A1450.

[4] M. Ise, K.D. Kreuer, J. Maier, Solid State Ionics 125 (1999) 213-223.

[5] J.S. Yi, T.V. Nguyen, J. Electrochem. Soc. 145 (1998) 1149-1159.

[6] S.H. Ge, B.L. Yi, J. Power Sources 124 (2003) 1-11.

[7] H. Li, Y. Tang, Z. Wang, Z. Shi, S. Wu, D. Song, J. Zhang, K. Fatih, J. Zhang, H. Wang, Z. Liu, R. Abouatallah, A. Mazza, J. Power Source 178 (2008) 103-117.

[8] Y. Wang, M. Ouyang, J. Power Sources 164 (2007) 721-729.

[9] D.T. Santa Rosa, D.G. Pinto, V.S. Silva, R.A. Silva, C.M. Rangel, Int. J. Hydrogen Energy 32 (2007) 4350-4357.

[10] Y. Zhang, A. Mawardi, R. Pitchumani, J. Power Sources 173 (2007) 264-276.

[11] L. Matamoros, D. Bruggemann, J. Power Sources 173 (2007) 367-374.

[12] S.U. Jeong, E.A. Cho, H.J. Kim, T.K. Lim, I.H. Oh, S.H. Kim, J. Power Sources 159 (2006) 1089-1094.

[13] S.U. Jeong, E.A. Cho, H.J. Kim, T.K. Lim, I.H. Oh, S.H. Kim, J. Power Sources 158 (2006) 348-353.

[14] H.K. Ma, S.H. Huang, Proceedings of the 4th International Conference on Fuel Cell Science, Engineering and Technology, 2006.

[15] X. Li, I. Sabir, Int. J. Hydrogen Energy 30 (2004) 259-371.

[16] X.D. Wang, Y.Y. Duan, W.M. Yan, X.F. Peng, J. Power Sources 175 (2007) 397-407.

[17] C. Xu, T.S. Zhao, Electrochem. Commun. 9 (2007) 497-503. 
[18] W.M. Yan, C.H. Yang, C.Y. Soong, F. Chen, S.C. Mei, J. Power Sources 160 (2006) 284-292.

[19] H.K. Ma, S.H. Huang, B.R. Chen, L.W. Cheng, J. Power Sources 180 (1) (2008) 402-409.

[20] H.K. Ma, S.H. Huang, J. Fuel Cell Sci. Technol., accepted on 21st, May, 2008. Paper no.: FC-07-1116.

$21]$ S. Shimpalee, J.W. Van Zee, Int. J. Hydrogen Energy 32 (2007) 842-856.

[22] Y.G. Yoon, W.Y. Lee, G.G. Park, T.H. Yang, C.S. Kim, Int. J. Hydrogen Energy 30 (2005) 1363-1366.
[23] S.U. Jeong, E.A. Cho, H.J. Kim, T.H. Lim, I.H. Oh, S.H. Kim, J. Power Sources 158 (2006) 348-353.

[24] T. Hottinen, O. Himanen, P. Lund, J. Power Sources 138 (2004) 205-210.

[25] CFD-ACE, CFD Research Corporation, 2004.

[26] W.W. Pulkrabek, Engineering Fundamentals of the Internal Combustion Engine, 2nd ed., Pearson Prentice Hall, 2003.

[27] V. Gurau, H. Liu, S. Kakac, AIChE J. 44 (11) (1998) 2410-2422. 